\title{
A BALANCED APPROACH TO CAPTURING USER REQUIREMENTS IN BUSINESS-TO- CONSUMER WEB INFORMATION SYSTEMS
}

\author{
M. S. Lane \\ A. Koronios \\ Department of Information Systems \\ University of Southern Queensland \\ Toowoomba, Australia \\ Email: lanem@usq.edu.au
}

\begin{abstract}
The development of business-to-consumer web information systems pose special challenges in the requirements analysis phase. It is difficult to capture user requirements given that users are relatively autonomous and anonymous and there are no major incentives for users to become involved in the development of a web information system. The researchers reviewed traditional requirement elicitation techniques, marketing research techniques and web usage analysis techniques. Current practice was assessed and the findings suggest that a balanced approach to user requirements capture will result in more complete and user centred requirements. This approach should lead to more effoctive business-to-consumer web information systems.
\end{abstract}

\section{Keywords}

Requirements elicitation, Requirements capture, Requirements analysis, Business-to-consumer electronic commerce; Web information systems

\section{INTRODUCTION}

The growth of the World Wide Web has seen the emergence of web based electronic commerce. The development of effective mass information systems such as web information systems is critical to the success of web based electronic commerce (Hansen 1995). Moreover, capturing user requirements is particularly important in the development of web information systems where user acceptance is often critical to the success of a web information system (Hansen 1995; Bauer \& Chong 1999).

This paper focuses on the capture of user requirements in the development of business-to-consumer web information systems. A review of requirements elicitation techniques, marketing research techniques and web usage analysis is conducted to evaluate the suitability of these techniques in the development of business-toconsumer web information systems. The paper proposes that a balanced approach to the capture of user requirements should result in more complete user requirements and the development of effective business-toconsumer web information systems.

The paper is structured as follows. First, business-to-consumer web information systems are defined. Then, the difficulty in capturing user requirements in these systems is highlighted. Next, traditional requirement elicitation techniques, marketing research techniques and web analysis techniques are assessed and the researchers argue for a balanced approach to the capture of user requirements that combines these techniques. Then, three cases are reviewed to provide a preliminary assessment of current practice's approach to the capture of user requirements in business-to-consumer web information systems. Finally there are some concluding remarks for research and practice, and the researchers outline plans for future work.

\section{BUSINESS-TO-CONSUMER WEB INFORMATION SYSTEMS}

Business-to-consumer web information systems are information systems based on web technology that support consumer interaction such as on-line shopping through integration with databases and transaction processing systems (Isakowitz, Bieber \& Vitali 1998). These systems rely on the hypertext functionality and transfer mechanisms of the World Wide Web and are characterised by interactivity, dynamic updating, hypertextuality and global presence (Scharl \& Brandrweiner 1998). In general, web information systems because of their open system platform look set to be the dominant information system for the next decade (Lyytinen, Rose \& Welke 1998). 


\section{CHALLENGE IN CAPTURING USER REQUIREMENTS}

While much of the traditional information system development approaches are applicable to business-toconsumer web information systems, the requirements analysis phase poses special challenges for these types of systems (Hansen 1995; Poulymenakou, Drakos, Papazafeiropoulou \& Doukidis 1998; Teubner \& Klein 1998). The increased organisational scope of business-to-consumer web information systems means that users are relatively anonymous and autonomous. The capture of user requirements is further complicated by the potential diversity that can exist in users as a key stakeholder group. For instance, users may vary from first time customers, regular customers, dissatisfied customers to the public at large. So how does one capture the requirements of users given that use is voluntary, the user is not readily accessible in person and there are no major incentives for the user to become involved in the development process?

In order to address this question, the researchers reviewed current knowledge in order to identify and assess the suitability of existing requirements capture methods, techniques and technologies.

\section{TRADITIONAL METHODS AND TECHNIQUES FOR CAPTURING USER REQUIREMENTS}

The researchers assessed a number of studies that have synthesised past requirements elicitation methodologies and techniques (Fazlollahi \& Tanniru 1991; Byrd, Cossick \& Zmud 1992). Fazlollahi and Tanniru (1991) revised Davis's (1982) contingency approach to the selection of a requirements elicitation methodology. The contingency approach is based on a three stage process. The first stage involves determining the level of uncertainty and the level of equivocality that exists in a system. Technology, organisational context and external environment can affect the level of uncertainty and equivocality that exists in a system. The completion of this stage provides guidance in selecting the appropriate information acquisition strategy to capture the information requirements. And finally a requirements elicitation methodology is chosen to implement the selected information acquisition strategy and capture the necessary information (Fazlollahi \& Tanniru 1991).

In the revised contingency approach, the information acquisition strategies are mapped on the appropriate requirements elicitation methodologies. These methodologies are classified into the following approaches: asking the user, understanding the current system, the utilising system and experimentation approaches. The elicitation methodologies and information acquisition strategies are summarised in table 1.

\begin{tabular}{|c|c|c|}
\hline $\begin{array}{l}\text { Requirements elicitation } \\
\text { methodologies }\end{array}$ & Information acquisition strategies & $\begin{array}{l}\text { Uncertainty/ } \\
\text { Equivocality }\end{array}$ \\
\hline $\begin{array}{l}\text { Asking the users } \\
\text { Closed questions } \\
\text { Open questions } \\
\text { Brain storming } \\
\text { Guided Brain storming } \\
\text { Group consensus } \\
\text { Interviewing } \\
\end{array}$ & $\begin{array}{l}\text { Asking the users } \\
\text { Special reports (controlled response) } \\
\text { Special reports (uncontrolled response) } \\
\text { Group meeting } \\
\text { Group meeting or Integrators } \\
\text { Group meeting or Integrators } \\
\text { Direct contact }\end{array}$ & \multirow{4}{*}{$\begin{array}{l}\text { High } \\
\text { equivocality } \\
\qquad \begin{array}{l}\text { Uncertainty } \\
\text { Equivocality } \\
\text { continuum }\end{array}\end{array}$} \\
\hline $\begin{array}{l}\text { Understanding current system } \\
\text { Documentation analysis }\end{array}$ & $\begin{array}{l}\text { Understanding the current situation } \\
\text { Rules and regulations; information systems }\end{array}$ & \\
\hline $\begin{array}{l}\text { Utilising system } \\
\text { Normative analysis } \\
\text { Strategy set transformation } \\
\text { Critical factors } \\
\text { Process analysis } \\
\text { Ends/Means analysis } \\
\text { Decision analysis } \\
\text { Socioeconomic analysis } \\
\text { Process analysis }\end{array}$ & $\begin{array}{l}\text { Utilising system } \\
\text { Information systems analysis; rule and regulations } \\
\text { Direct contact, group meeting; integrators } \\
\text { Planning; special reports, direct contact } \\
\text { Planning, information analysis, special reports } \\
\text { Planning, direct contact; information systems analysis } \\
\text { Direct contact; information systems analysis } \\
\text { Information systems analysis; rules and regulations } \\
\text { Information systems analysis; rules and regulations }\end{array}$ & \\
\hline $\begin{array}{l}\text { Experimentation } \\
\text { Prototyping or heuristic methods }\end{array}$ & $\begin{array}{l}\text { Experimentation } \\
\text { Direct contact; planning }\end{array}$ & \\
\hline
\end{tabular}

Table 1 Mapping of Requirements elicitation methodologies and information acquisition strategies (Source: adapted from Fazlollahi \& Tanniru 1991, p. 299)

The level of uncertainty and equivocality existing in the problem domain of a system determines the suitability of different types of requirements elicitation methodologies. Asking the user is more appropriate in situations where high levels of equivocality exists while experimenting with prototypes is more appropriate in situations where more information is required to reduce uncertainty.

Byrd et al. (1992) provided a comprehensive synthesis of requirements analysis techniques. The requirements 
analysis techniques were classified into five distinction categories: observation techniques, unstructured elicitation techniques, mapping techniques, formal analysis techniques and structured elicitation techniques. Observation techniques consist of behaviour analysis, protocol analysis and prototyping. Unstructured elicitation techniques consist of teach-back interviewing, open interviews, brainstorming using the collective decisionmaking approach and the goal-oriented approach. Mapping techniques consist of multi-dimensional scaling, cognitive mapping, and variance analysis. Formal analysis techniques include techniques such as text analysis and repertory grids while structured elicitation techniques include techniques such as: card sort, scenario analysis, structured interviewing, critical success factors and future analysis.

The different requirements elicitation techniques that fell within these five categories were mapped onto the problem domain, locus of control and communication obstacles in which these requirements elicitation techniques might be used most effectively. The mapping of these five categories is presented in table 2 and a discussion of the problem domain, locus of control, and communication obstacles follows.

\begin{tabular}{|l|l|l|l|}
\hline \multicolumn{4}{|c|}{ Problem domain legend : IR = Information requirements; PU = Process understanding; } \\
BU = Behaviour understanding; PFU = Problem frame understanding
\end{tabular}

Table 2 Categorisation scheme for requirements elicitation methodologies (Source: adapted from Byrd et al. 1992)

Problem domain categories. Many different elicitation techniques are used to gain understanding of the domain problem. In order to compare different elicitation techniques, these techniques have been grouped into the following problem domain categories (Byrd et al. 1992): information requirements, process understanding, behaviour understanding, and problem frame understanding.

Information requirements is concerned with the information requirements of the proposed information system such as the information to be displayed to the user in soft copy (visually presented on screen) or hard copy (printed reports).

Process understanding is concerned with an analysis of the business processes that will affect or be affected by the proposed information system. This would include the facts, rules, beliefs, algorithms and procedures pertinent to business processes, factors that may inhibit design, development and implement of the proposed information system.

Behaviour understanding focuses on the dynamic nature of data and knowledge and the need to analyse and understand events in the environment that impact on data and knowledge recorded in the proposed information system (Byrd et al. 1992). Behaviour understanding involves mental models and operational models which are abstractions of problem domain from both user perspective and input/output processes perspective.

Problem frame understanding is concerned with understanding the overall context in which the system is being developed. For instance, the business objectives and goals that the proposed information system should address and the existing technological environment which will be used to support the proposed information system.

Locus of control in the requirements engineering process can be user driven, analyst driven, joint participation 
(user, analyst), or automated (Byrd et al. 1992). User driven means that requirements elicitation process is driven by the user. Typically, the requirements elicitation process was driven by the system analyst. In more recent times there has been a move toward joint participation in requirement elicitation process in information systems that are socio-technical in nature (Byrd et al. 1992). Information systems that are socio-technical in nature imply the involvement of people in the day-to-day operations of an information system. There has also been some progress in the automation of the requirements elicitation process in certain contexts. For instance, the requirements of users in web information systems can be derived from the analysis of the web server log files. Overall, there is a tendency for locus of control to be analyst driven in the development of web information systems where the analyst/web developer builds a system from client specifications without any input from the users (Loh \& Pendse 1997).

Communication obstacles consist of three different obstacles: within, between and among. These three obstacles can inhibit the communication process in requirements elicitation. Within obstacles involve the cognitive limitations of humans as information processors and problem solvers (Davis 1982; Valusek \& Fryback 1985). People specifying information requirements are subject to limited memory and recall as well as information processing biases such as selective perception or representativeness. Elicitation techniques that focus on within communication obstacles concentrate on enhancing recall and understanding a user's innate information processing activities and decision processes.

Between obstacles. Cognitive limitations also contribute to communication difficulties between system analysts and end users. These communication difficulties are referred to as between obstacles. The communication problems are not only caused by individual cognitive limitations but also by a lack of common language (Davis 1982; Valusek \& Fryback 1985).

Between obstacles are addressed by elicitation techniques designed to aid the participants communication process. Such techniques are often an attempt to create a mutually understood context or provide a means to otherwise facilitate the interaction process. Much of the anecdotal evidence suggests that there is little involvement of the users in the development of web information systems. Communication between users and web developers is a neglected issue in the current web information systems development practices, but this is understandable because of the difficulties in involving users in the development process.

Among obstacles. Even if these previous obstacles are addressed one may still be confronted with balancing the needs of multiple stakeholders (Byrd et al. 1992). A system designed for multiple stakeholders must attempt to accommodate each stakeholder's needs which can be in conflict with other stakeholders' needs or be in competition for limited system design resources. Among obstacles require tradeoffs and weighting of multiple needs after determining individual requirements. The requirement elicitation techniques that address among obstacles incorporate the varying views of distinct stakeholders. These techniques also provide mechanisms by which stakeholders can negotiate and reach an consensus regarding a collective set of needs. The diversity and large number of stakeholders involved both directly and indirectly with a web information system means that among obstacles is important issue in the management of the requirements of a business-to-consumer web information system.

Managing the requirements elicitation process - methodologies. The use of methodologies in requirements engineering is problematic in that there are a number of issues to consider in applying a suitable requirements engineering methodology. Firstly, there are different categories of problem domains, which will require different requirements analysis techniques. Secondly, the locus of control will vary depending on the technique(s) used and communication obstacles that are encountered (Byrd et al. 1992). Technical, organisational and environment aspects of the problem domain of a proposed information system will influence the level of uncertainty and equivocality confronting system developers (Fazlollahi \& Tanniru 1991). The choice of the appropriate requirements elicitation methodology and accompanying information acquisition strategy will be dependent on the above mentioned factors.

\section{MARKET APPROACH TO CAPTURING USER REQUIREMENTS}

More recently researchers have suggested that marketing research techniques provide a variety of approaches that address the difficulty in capturing user requirements in web information systems (Hansen 1995; Bauer \& Chong 1999). These include collection, processing and analysis of market data from primary and secondary sources to identify customer needs; prototyping; observation of and interviews with test users; test markets; statistical analysis of usage data; and periodical polls with questionnaires (Hansen 1995). Table 3 provides an assessment of the suitability of the marketing research techniques in terms of feasibility and cost for web information system development. The assessment of the different marketing research techniques is a subjective evaluation of their effectiveness in gathering the user requirements in the development of business-to-consumer web information systems. 


\begin{tabular}{|c|c|c|}
\hline Techniques & Feasibility & Cost \\
\hline \multicolumn{3}{|l|}{ Exploratory techniques } \\
\hline Interviewing techniques & Medium & High \\
\hline Projective techniques & High & High \\
\hline Observational techniques & Medium & Medium \\
\hline \multicolumn{3}{|l|}{ Problem solving research techniques } \\
\hline Longitudinal consumer panel & Medium & Low \\
\hline Mail surveys & High & Medium \\
\hline Telephone surveys & Medium & High \\
\hline Personal interviews & Low & High \\
\hline On-line surveys & High & Low \\
\hline Personal observation & Low & High \\
\hline Mechanical and unobtrusive observation & High & Low \\
\hline
\end{tabular}

Table 3 Assessment of the suitability of marketing research techniques for web site development (Source: adopted from Bauer \& Chong 1999, p. 421)

Similar to Fazlollahi and Tannin 's (1991) classification, exploratory techniques are more suited to dealing with situations of high equivocality which require richer and not necessarily more information while problem solving research techniques are more suited to situations of high uncertainty requiring more information. There is considerable overlap between the requirements elicitation methodologies discussed in the previous section and the marketing research techniques that have been highlighted in table 3 . It would appear that the use of requirements elicitation techniques that involve asking the user have been neglected due to the evolution of web information systems from a grass roots and spontaneous effort and the relative autonomy and anonymity of the users. Mechanical observation relies on non-human devices to record people's behaviour. The Internet and the Web provide the opportunity to collect more information about the user than many realise. Nevertheless the potential for collecting data using mechanical observation has been neglected and/or under-estimated by many firms (Bauer \& Chong 1999).

\section{CAPTURING USER REQUIREMENTS WTTH WEB ANALYSIS TOOLS}

Web analysis tools provide a valid way to capture and analyse user behaviour and activity in web information systems. These tools allow web developers to draw inferences from the analysis of user activity and behaviour on-line which can be used to develop and evaluate user requirements. Technologies such as cookies, log-file statistics or click stream analysis can provide a clear picture of user behaviour right down to the individual. User information collected on-line tends to be more useful for the re-development and evolution of a web information system rather than for the initial start-up phase. There are a number of studies that have assessed the suitability of these tools in the development of web information systems (e.g. Bertot \& McClure 1997; Wu, Yu \& Ballman 1998; Bauer \& Scharl 1999). A discussion of these studies follows.

Bertot and McLure (1997) discuss analytical techniques that use web usage to determine user behaviour in relation to a web information system. Web servers automatically generate and dynamically update four usage log files. These $\log$ files capture the following information in relation to user activity: (1) Access log records the date, time, IP address and items accessed by the user; (2) Agent log provides data on a user browsers, browser version and operating system; (3) Error log records abort enrors (4) Referrer log indicates what other sites on the Web are linked to the web information system.

The following information can be obtained from the access log file: total number of daily and weekly accesses and hits; average daily accesses and hits; percentage of accesses and hits generated by web information system; percentage of accesses and hits experienced from within a country and from overseas countries; and specific path that a user takes through a server per session. A hit is a particular item downloaded from a web page whereas a access is recorded when a user downloads an entire web page. It is important to distinguish between the number of hits and accesses as the number of hits recorded in a access $\log$ file can be misleading. For instance, a firm may have their corporate logo image on every web page, hence that image is likely to be the most frequently downloaded hit item on a web site.

From the agent log file, it is possible to determine the type and version of browsers used to access a web server and the type of operating system of the computer used to access the web server. This data is particularly 
important as it indicates the access and display capabilities of the users. Web developers should develop web information systems that meet the technical capability of the majority of users.

With the referrral log file it is possible to determine the total and unique number of referring IP addresses; and the most frequently referring web sites. This data allows web developers to notify most frequently referring sites when it is necessary to update their links to avoid user encountered error messages.

The error log file provides information on errors (e.g. dead links- error 404 and aborted file downloads) that users encounter or initiate. Analysis of the error log file can provide information such as the occurrence of missing files, erroneous links and aborted downloads. Images, files and pages that are slow to download leading users to abort the file download are identified in the error $\log$ file as aborted downloads. This is important information as it allows developers to modify and correct content, thus decreasing the number of errors that a user will encounter in navigating the hypertext structure of a web information system.

Cookies and user login ids can be used to identify a user session when accessing a web system (Wu et al. 1998). There is considerable resistance by some users to monitoring their activity online due to privacy concerns. The speed tracer is a web usage, mining and analysis tool that can record a user session without the use of cookies or a user id. Speed tracer provides user-oriented statistics such as most frequent external referrals, most frequently visited pages, distributions of user session duration and the number of pages visited.

There are ethical and privacy issues that may impact on these mechanical observation approaches. As the Internet matures as a business medium, privacy legislation may restrict such approaches in the future. In Australia, recent legislation has been passed that restricts the collection and use of online customer information without the consent and prior knowledge of the person involved.

\section{A BALANCED APPROACH TO REQUIREMENTS CAPTURE}

The researchers argue that in order to facilitate the capture and management of user requirements in business-toconsumer web information systems, IS professionals need to combine traditional requirements elicitation techniques, market research techniques and web usage analysis techniques. Many of the traditional requirements elicitation techniques and market research techniques are reliant on the cooperation and involvement of users. On the other hand, web usage analysis techniques use mechanical observation techniques for constant capture of user activity but these techniques are reliant on there being sufficient user activity in a system. And in the future, privacy legislation may curtail automated capture of user activity through web server log files and cookies. Therefore, given the nature of web information systems and relative autonomy and anonymity of users, using a balanced approach that combines these techniques will facilitate capture and management of user requirements. Traditional and marketing requirements capture techniques are used initially to identify the target market that exists online and periodic polling of the target market is necessary to ensure that marketing strategies are working effectively. Mechanical observation techniques complement traditional requirements elicitation and market research techniques in that they provide continuous assessment of user requirements through analysis and inference of user activity (Bauer \& Chong 1999). Such a balanced approach addresses the equivocality and uncertainty faced in capturing the user requirements of business-to-consumer web information systems that are constantly evolving. The reiterative nature of requirements capture has been acknowledged by numerous researchers (Loucopoulos \& Karakotsas 1995; Somerville 1996) and given that the balanced approach advocated by the researchers includes sociological and technical techniques, the multiview methodology would accommodate such an approach (Avison \& Wood-Harper 1990).

\section{RESEARCH ISSUE AND METHOD}

This study was designed to investigate the techniques used to capture user requirements in business-to-consumer web information systems. The business-to-consumer web information systems pose special challenges regarding the capture of user requirements. The global scope and voluntary use of such systems, and the relatively autonomous and anonymous nature of users means that user requirements are difficult to capture. Hence, the research issue is defined as "the assessment of requirement capture techniques used in the development of business-to-consumer web information systems". Of particular interest to the researchers is the degree to which firms are using traditional requirements capture techniques, marketing research techniques and web usage analysis techniques in the ongoing development of business-to-consumer web information systems. The identification and assessment of requirements capture techniques will assist in identifying best practice in the capture and management of user requirements.

A qualitative approach was deemed appropriate as this research is in the exploratory stages and there is a lack of empirical research on requirements capture and management in business-to-consumer web information systems (Galliers 1994, Yin 1994). In the first phase of this research, data collection involved analysis of three businessto-consumer web information systems with the aim of providing a preliminary assessment of requirements capture techniques currently used in practice. Data was collected in a series face-to-face interviews with senior 
management, marketing management and system/analysts in three firms that actively involved in business-toconsumer electronic commerce.

\section{ASSESSMENT OF REQUIREMENTS CAPTURE IN THREE CASES}

The results of these case interviews were analysed by the researchers. The details of the three cases are presented in table 4 and a brief discussion of each case follows.

\begin{tabular}{|l|l|l|l|}
\hline Case & Case A & Case B & Case C \\
\hline Product & Business Software & Health Products & Film Processing \\
\hline Years in operation & 13 & 20 & 23 \\
\hline Number of employees & 30 & 100 & 78 \\
\hline
\end{tabular}

Table 4. Details of the three cases

Case $\mathbf{A}$ is a small company that publishes, republishes and distributes business software to a number of large retailers. Case $A$ also sells software directly to customers by mail order and uses the Internet as additional marketing channel. Case B is a medium sized company which manufactures and direct markets health products by mail order. The web information system is seen as complementary to its existing marketing channels and Case B wants to be strategically placed for the expected growth of the Internet as a marketing channel. Case B believe that their product is a good fit for the Internet. Case $\mathrm{C}$ is medium sized company that provides film processing services by mail order and is using the Internet to complement this service. Case $C$ see the Internet as an excellent delivery vehicle for their products as the film processing industry is starting to embrace digital processing.

The development practices of the three firms were assessed with regard to requirements capture techniques and tools these cases were using in the ongoing development of their web information systems. The requirements capture techniques used by the three cases are presented in table 5 and a discussion of these techniques follows.

\begin{tabular}{|c|c|c|c|}
\hline & Case A & Case B & Case C \\
\hline Locus of control & Analyst/web developer & Analyst/web developer & Analyst/web developer \\
\hline $\begin{array}{l}\text { Communication } \\
\text { obstacles }\end{array}$ & $\begin{array}{l}\text { Within communication } \\
\text { not addressed } \\
\text { Poor communication } \\
\text { between web } \\
\text { developers and users } \\
\text { Multiple stakeholders } \\
\text { requirements poorly } \\
\text { addressed }\end{array}$ & $\begin{array}{l}\text { Within communication } \\
\text { not addressed } \\
\text { Poor communication } \\
\text { between web developers } \\
\text { and users } \\
\text { Multiple stakeholders } \\
\text { requirements addressed } \\
\text { to some extent }\end{array}$ & $\begin{array}{l}\text { Within communication not } \\
\text { addressed } \\
\text { Poor communication } \\
\text { between web developers and } \\
\text { users } \\
\text { Multiple stakeholders } \\
\text { requirements addressed } \\
\text { to a greater extent }\end{array}$ \\
\hline $\begin{array}{l}\text { Traditional } \\
\text { requirements } \\
\text { elicitation techniques }\end{array}$ & $\begin{array}{l}\text { Goal oriented approach } \\
\text { User feedback - email }\end{array}$ & $\begin{array}{l}\text { Goal oriented approach } \\
\text { Critical success factors } \\
\text { User feedback - email }\end{array}$ & $\begin{array}{l}\text { Goal oriented approach } \\
\text { Critical success factors } \\
\text { User feedback - email }\end{array}$ \\
\hline $\begin{array}{l}\text { Marketing research } \\
\text { techniques }\end{array}$ & Online surveys & Online surveys & Online surveys \\
\hline $\begin{array}{l}\text { Web usage } \\
\text { analysis techniques }\end{array}$ & ISP Web server log files & $\begin{array}{l}\text { Own web server log files } \\
\text { Cookies identify user } \\
\text { sessions }\end{array}$ & $\begin{array}{l}\text { ISP Web server log files } \\
\text { Monitor bandwidth utilisation } \\
\text { Cookies and user id identify } \\
\text { user sessions }\end{array}$ \\
\hline
\end{tabular}

Table 5 Requirements elicitation techniques, market research techniques and web usage analysis techniques used in the three cases

In all three cases, development was driven by the analyst/web developer which supports the findings of the study by Loh and Pendse (1997). They found that there was a tendency for web developers to build web systems based on client specifications with little input from the users of such systems. This can be explained in part by the evolutionary nature of web information systems which have evolved from a simple information presence to supporting business transactions, communication and distribution. As these systems realise their commercial potential, it is becoming increasingly important to consider the user in the development of these systems.

The lack of user involvement in these systems indicates that communication between the users and the web developers is limited. Generally, there was a lack of involvement of users in the development process although cases $B$ and $C$ considered a wider range of stakeholders in business-to-consumer web information systems.

In all three cases, the requirements of the web information system was driven by business goals and objectives. Cases $B$ and $C$ also focused on the critical success factors for selling the products and services online as these 
firms were much more proactive in selling online whereas case $\mathrm{C}$ saw their web information system as providing support for their products. Although user involvement was limited, all three firms received some email feedback from users concerning the design and performance of their systems. The information received was of a voluntary nature, none of the firms had considered capturing requirements explicitly from users and were more interested in capturing marketing information from the users.

User activity and to a lesser extent user behaviour in each case's web information system was analysed from web server $\log$ files. The $\log$ files were mainly used to analyse web traffic such as frequency of particular pages accessed and frequency of referring links. Cases $B$ and $C$ were able to analyse individual user activity to a greater degree due to the use of cookies and user ids which allows them to identify a particular user session. At present, this information is mainly used for tracking orders placed by online customers. Case $C$ is also using the information to provide a personalised experience for the customer.

\section{PRELIMINARY FINDINGS AND CONCLUSIONS}

There appears to be little involvement of users in the definition and specification of the requirements in businessto-consumer web information systems. The requirements elicitation process appears to be largely analyst driven where analysts/consultants develop a web information system from the client's specifications namely senior management. The requirements elicitation methods define the system from the existing or current situation, recipients of the system, or through experimentation of a constantly evolving system. The user requirements were largely defined from senior management and web developer perspectives, by analysing web server log files and through limited voluntary feedback from users.

There appears to be considerable scope for web developers to actively elicit requirements from users and for web developers to better utilise user activity and user behaviour which is implicitly recorded on web server log files.

Overall, traditional requirements elicitation techniques provide a rich and varied source of methods for capturing user requirements. The marketing research techniques complement the marketing nature of business-toconsumer electronic commerce and add another dimension to existing requirement elicitation techniques. The mechanical observation techniques such as web usage analysis techniques are important as they allow web developer to capture and evaluate user requirements by monitoring user activity on web information systems. A balanced approach to the capture of user requirements that incorporates traditional requirements elicitation techniques, market research techniques and web usage analysis techniques should provide a more complete set of user requirements and lead to development of business-to-consumer web information systems that are user centred and effective.

\section{FUTURE WORK}

Further work is needed to fully assess the usage and viability of traditional requirement elicitation techniques, market research techniques and web usage analysis techniques in the capture of user requirements in business-toconsumer web information systems. The researchers will conduct a number of case studies across the different segments of the online retail market. This will allow the researchers to validate the usefulness of combining existing traditional requirements elicitation techniques and marketing research techniques with the mechanical observation of user activity and behaviour. The suitability of multiview methodology to support such an approach will also be evaluated. It is envisaged that an additional outcome of these confirmatory cases will be the development of a survey instrument to assess the requirements engineering process in web information systems.

\section{REFERENCES}

Avison, D. E. and Wood-Harper (1990) Multiview: An Exploration in Information Systems Development, McGraw-Hill, Maidenhead.

Bauer, C. and Scharl, A. (29 ${ }^{\text {th }}$ November 1999) Development of Web information systems: conceptual models and examples from the retail financial services industry, Proceedings of $3^{\text {rd }}$ Annual CollEcter Conference on Electronic Commerce, Wellington, New Zealand.

Bauer, C. and Chong, S. (June 1999) Electronic Markets Development: Using Marketing Research to Determine User Requirements, in: Global Networked Organisations, Proceedings of $12^{\text {th }}$ BLED Electronic Commerce Conference, Bled, Slovenia, pp. 408-423.

Bertot, J. and McClure, C. R. (1997) Web usage statistics: measurement issues and analytical techniques, Government Information Quarterly, 14:4, pp. 373-390.

Byrd, T., Cossick, K. and Zmud, R. (March 1992) A Synthesis of Research on Requirements Analysis and Knowledge Acquisition Techniques, MIS Quarterly, 16:1, pp. 117-138. 
Davis, G. (1982) Strategies for Information Requirements Determination, IBM Systems Journal, 21:1, pp. 4-30.

Fazlollahi, B. and Tanniru, M. R. (1991) Selecting a requirements determination methodology-contingency approach revisited, Information and Management, 21:5, pp. 291-303.

Galliers, R. (1994) Choosing Information Systems Research Approaches, in: G. R. Henley on Thames (Ed) Information Systems Research: Issues, Methods and Practical Guidelines, Alfred Walker, pp. 144-162 .

Hansen, H. R. (1995) Conceptual framework and guidelines for the implementation of mass information systems, Information \& Management, 28:2, pp. 125-142.

Isakowitz, T., Bieber, M. and Vitali, F. (July 1998) Web information systems, Communications of the $\mathbf{A C M}$, 41:7, pp. 78-80.

Lyytinen, K., Rose. G and Welke, R. (July 1998) The brave new world of development in the internetwork computing architecture (InterNCA): or how distributed computing platforms will change systems development, Information Systems Journal, 8:3, pp. 241-253.

Loucopoulos, P and Karakotsas, V. (1995) Systems Requirement Engineering, McGraw-Hill, Berkshire, UK.

Poulymenakou, A., Drakos, W., Papazafeiropoulou, A. and Doukidis, G. (November 1998) Towards new web application development practices, Australian Journal of Information Systems (Special Edition Electronic Commerce), pp. 107-113.

Scharl, A. and Brandtweiner, R. (1998) A conceptual research framework for analysing the evolution of electronic markets, Electronic Markets, 8:2, pp. 39-42.

Somerville, I. (1996) Software Engineering $5^{\text {th }}$ Ed, Addison and Wesley, New York.

Teubner, R. A. and Klein, S. (November 1998) Planning and designing web-based electronic commerce: a case study in the insurance industry, Australian Journal of Information Systems, Special Edition - Electronic Commerce, pp. 86-96.

Toh, L. and Pendse, S. An empirical evaluation of web page design and consumer behaviour, Proceedings of 1997 ColleCTer conference, [Online], Available: http://www.collecter.org/Coll97/toh.pdf, [Accessed $8^{\text {th }}$ May 2000].

Valusek, J. R. and Fryback, D. G. (1987) Information Requirements Determination: Obstacles within, Among and Between, in: R. Galliers (Ed) Information Analysis: Selected Readings, Reading, MA, AddisonWesley, pp. 139-151.

Wu, K. L., Yu, P. S. and Ballman, A. (1998) Speed tracer: A web usage mining and analysis tool, IBM Systems Journal, 37:1, pp. 89-106.

Yin, R. K. (1994) Case Study Research - Design and Methods, Thousand Oaks, California, Sage. 